\title{
NICARAGUA Y LA INVASIÓN DE 1955 EN LOS DISCURSOS DE LA PRENSA COSTARRICENSE
}

\author{
Alexia Ugalde Quesada
}

Recibido: 15/06/2015 Aceptado: 23/10/2015

\begin{abstract}
Resumen
El propósito de este artículo es inspeccionar los discursos y las representaciones que se construyeron en la prensa en torno a la invasión a Costa Rica en enero de 1955. En primer lugar, se exploran los actores políticos que participaron o se vieron involucrados en el conflicto. Además, se analiza el uso de propaganda en los reportes oficiales del gobierno de Costa Rica y cómo esta es utilizada para inspirar y mantener en el campo de batalla a un ejército de voluntarios. Al final del artículo, se muestra cómo los periódicos informaron sobre las victorias y las derrotas del gobierno costarricense, poniendo en un primer plano a las primeras y en muchos casos ocultando o justificando a las segundas. Por último, este artículo intenta contribuir a la reflexión sobre la relación histórica entre Costa Rica y Nicaragua.
\end{abstract}

Palabras clave: Invasión 1955; José Figueres Ferrer; Nicaragua; Anastasio Somoza; Rafael Ángel Calderón Guardia; Otilio Ulate; comunistas; propaganda.

\begin{abstract}
This essay's purpose is to present the discourses and representations contained in the Costa Rican media about the invasion to Costa Rica in January of 1955. First, it explores the political actors who participated in the conflict. Furthermore, it analyzes the use of propaganda in the official reports and how the Costa Rican government tried to inspire and keep in the field a volunteer army. At the end, it shows how the newspapers published the information about the Costa Rican government victories in a central place, and the defeats were hidden and concealed. Finally, this paper also was a contribution to the reflection about the historical relationship between Costa Rica and Nicaragua.
\end{abstract}

Keywords: Invasion 1955; José Figueres Ferrer; Nicaragua; Anastasio Somoza; Rafael Ángel Calderón Guardia; Otilio Ulate; communists; propaganda.

Durante el primer gobierno constitucional de José Figueres Ferrer, en una sociedad marcada por la Guerra Civil de 1948, el 11 de enero de 1955 se dio una invasión dirigida principalmente por "los vencidos", es decir, los calderonistas con apoyo de algunas de las dictaduras de América Latina. Dicha incursión de fuerzas armadas al 
territorio costarricense desde Nicaragua fue una de las diversas manifestaciones de la inestabilidad y la violencia política que se vivió en Costa Rica durante la posguerra.

Este conflicto se enmarca en la conocida enemistad entre José Figueres Ferrer y Anastasio Somoza. Sin embargo, también permite acercarse a la comprensión de las relaciones entre Costa Rica y Nicaragua, dándole una perspectiva histórica a los conflictos que han caracterizado a ambos países, visibilizando la construcción de valores identitarios para el caso costarricense y de representaciones (los cuales pueden ubicarse en el presente), que sin duda han alimentado los estereotipos y la xenofobia hacia los nicaragüenses.

Para analizar este conflicto se consultaron cinco periódicos como fuente primaria: La Nación, el Diario de Costa Rica, La República, el Eco Católico y Adelante. La elección de estos se debió a sus diferentes posiciones políticas, las cuales son de vital importancia para comprender sus discursos; el Diario de Costa Rica tenía una posición antifiguerista por pertenecer a Otilio Ulate, que para el periodo se encuentra enemistado con Figueres, La República era un medio progobierno, La Nación, en comparación con los anteriores intentaba ser más neutral; el Eco Católico pertenecía a la Iglesia católica y Adelante era una publicación dirigida por los comunistas.

Se partirá de la propuesta de Schweizer y Schumann (2008), quienes argumentan que los periódicos influyen en la opinión pública particularmente en la comprensión de cómo se desarrolla la guerra, al asegurar que los acontecimientos narrados en un periódico sobre una enfrentamiento militar son cuidadosamente escogidos en función de un argumento que promueve una política o personalidad en particular. Por lo anterior, es fundamental considerar que cada periódico que se utilizará presenta una interpretación de los eventos caracterizados por su alto grado de subjetividad y por articular su discurso en función de los intereses de la línea editorial.

El periodo de estudio escogido es de diciembre de 1954 a febrero de 1955 para tener referencia de lo que sucedió antes y después de la invasión. En general, estos periódicos tienen un gran acceso, sin embargo, lamentablemente Adelante no se publicó entre el 9 de enero y el 13 de marzo de 1955, por lo que se decidió ampliar el periodo desde noviembre de 1954 hasta marzo de 1955. La metodología utilizada para analizar la información fue el análisis de discurso, la cual plantea que el lenguaje puede regular las relaciones sociales y afectar la realidad social.

Este trabajo se divide en tres apartados, en el primero se analizarán los discursos creados en torno a los personajes que participaron o se vieron involucrados en el conflicto y las características que se les atribuyeron. En el segundo apartado se trabajará en los discursos patrióticos y de motivación dirigidos a los combatientes del Gobierno, entre los que se destaca la utilización de eventos históricos como la Campaña Nacional de 1856 y la invasión de diciembre de 1948. Por último, en el tercer apartado se identificará la forma de narrar las victorias y las derrotas de ambos bandos. 


\section{Participantes en la invasión calderonista de 1955}

En este primer apartado se analizarán los discursos presentes en la prensa costarricense con respecto a los personajes que participaron o se vieron involucrados en la invasión calderonista de enero de 1955, considerando tanto personajes particulares como colectividades. Específicamente, se hará énfasis en los discursos sobre Nicaragua, Anastasio Somoza, Costa Rica y José Figueres, quien era presidente en el momento del conflicto; Rafael Ángel Calderón Guardia, los calderonistas, los comunistas, Otilio Ulate, $\mathrm{y}$, por último, se estudiarán los discursos sobre los combatientes de ambos bandos, es decir, los invasores, los gobiernistas y el fortalecimiento militar de cada uno de ellos.

\section{Nicaragua y Anastasio Somoza}

La invasión de 1955 fue mostrada en los discursos de los periódicos como un conflicto a nivel nacional e internacional, esta última interpretación involucraba directamente a Nicaragua y a otros países como República Dominicana y Venezuela. Sin embargo, la denuncia efectuada por Costa Rica ante la Organización de Estados Americanos (OEA), días antes de la incursión al territorio costarricense, planteó específicamente "la inminencia de una agresión a Costa Rica desde Nicaragua" (La Nación, 08 de enero de 1955: 5).

Los rumores de una posible invasión por parte de los calderonistas o del gobierno nicaragüense a Costa Rica tenían meses de formar parte de los debates periodísticos, la inestabilidad política en Costa Rica generaba un ambiente de inseguridad, intranquilidad y temor a una nueva guerra civil o un conflicto de carácter internacional, más considerando que Costa Rica desde el 1 de diciembre de 1948 había proscrito el ejército.

Suonpää (2010) argumenta que los periódicos reflejan los discursos populares contemporáneos y los estereotipos comunes que se tienen hacia otras poblaciones o países, exagerando los aspectos "negativos". Al comprender los estereotipos como categorías que se forman sobre la base de diversas características culturales, de acuerdo con las ideas que las personas crean sobre sí mismas y sobre los otros; estas categorías son a menudo muy subjetivas y selectivas, además de que, los estereotipos exageran los aspectos negativos y despectivos. ${ }^{1}$

Por lo anterior, es de suma importancia conocer cuáles representaciones se hicieron de los combatientes invasores y, específicamente, de Nicaragua y Anastasio Somoza durante este conflicto, prestando especial interés a los cambios que puedan existir en los atributos, adjetivos o juicios de valor utilizados antes, durante y después de la invasión de 1955 y las respectivas comparaciones con Costa Rica.

Desde el mes de diciembre anterior a la invasión, se presentó a Nicaragua como el país desde donde se estaba planeando el ingreso al territorio costarricense, 
se decía que desde ahí se reclutaría a los hombres que participarían en la invasión. La República, el periódico con un discurso oficialista, fue donde más características negativas se atribuyeron a Somoza. Por el contrario, en el Diario de Costa Rica existió un especial cuidado a la hora de hablar de este personaje y se presentan pocos atributos negativos.

El periodo de estudio de este trabajo se caracteriza por una latente tensión entre los dos gobiernos pues, como plantea González (2005), el territorio de Costa Rica en esa época fue utilizado para organizar grupos insurgentes contra la dictadura de Anastasio Somoza y a su vez el territorio vecino de Nicaragua sirvió para albergar grupos opositores al gobierno de Figueres que en varias oportunidades invadieron Costa Rica. Para José Luis Torres (1986), Somoza, a quien le inquietaba la presencia de Figueres en Costa Rica, dispuso dar el más amplio apoyo a los exiliados calderonistas que pretendían invadir el país, con la ayuda también de otras dictaduras latinoamericanas.

Son frecuentes las acusaciones personales entre Figueres y Somoza, mientras el primero aseguraba que el nicaragüense estaba planeando una invasión a Costa Rica, que quería disfrazar de un conflicto político interno, ${ }^{2}$ el segundo afirmaba no estar interfiriendo en asuntos internos de Costa Rica y negaba cualquier relación con los invasores, por el contrario decía que era el Gobierno de Costa Rica el que quería involucrar a Nicaragua en un conflicto político que en realidad era una revolución interna, con el propósito de darle carácter internacional. ${ }^{3}$

Como apunta Suonpää (2010), la propaganda en tiempos de guerra mediante la prensa refleja una gran cantidad de discursos contemporáneos y populares, a partir de esta propuesta, se considera que muchos de los atributos encontrados sobre Nicaragua y Somoza no solo eran parte de los discursos de la prensa sino también de las características que la población costarricense les atribuía.

De acuerdo con la prensa, la principal acusación a Somoza fue la de apoyar la invasión al abrir sus fronteras a los invasores, facilitarles armas y además organizar su entrenamiento. Por su parte, en el periódico Adelante, los comunistas declararon que el autor de la invasión era el general Anastasio Somoza. ${ }^{4}$ Como se observa en la imagen 1, Nicaragua es representada como el lugar donde se encuentran los hombres que invadirán y Somoza es representado como quien ha permitido que permanezcan en el país y ante la presencia de la OEA los expulsa para no verse involucrado. 


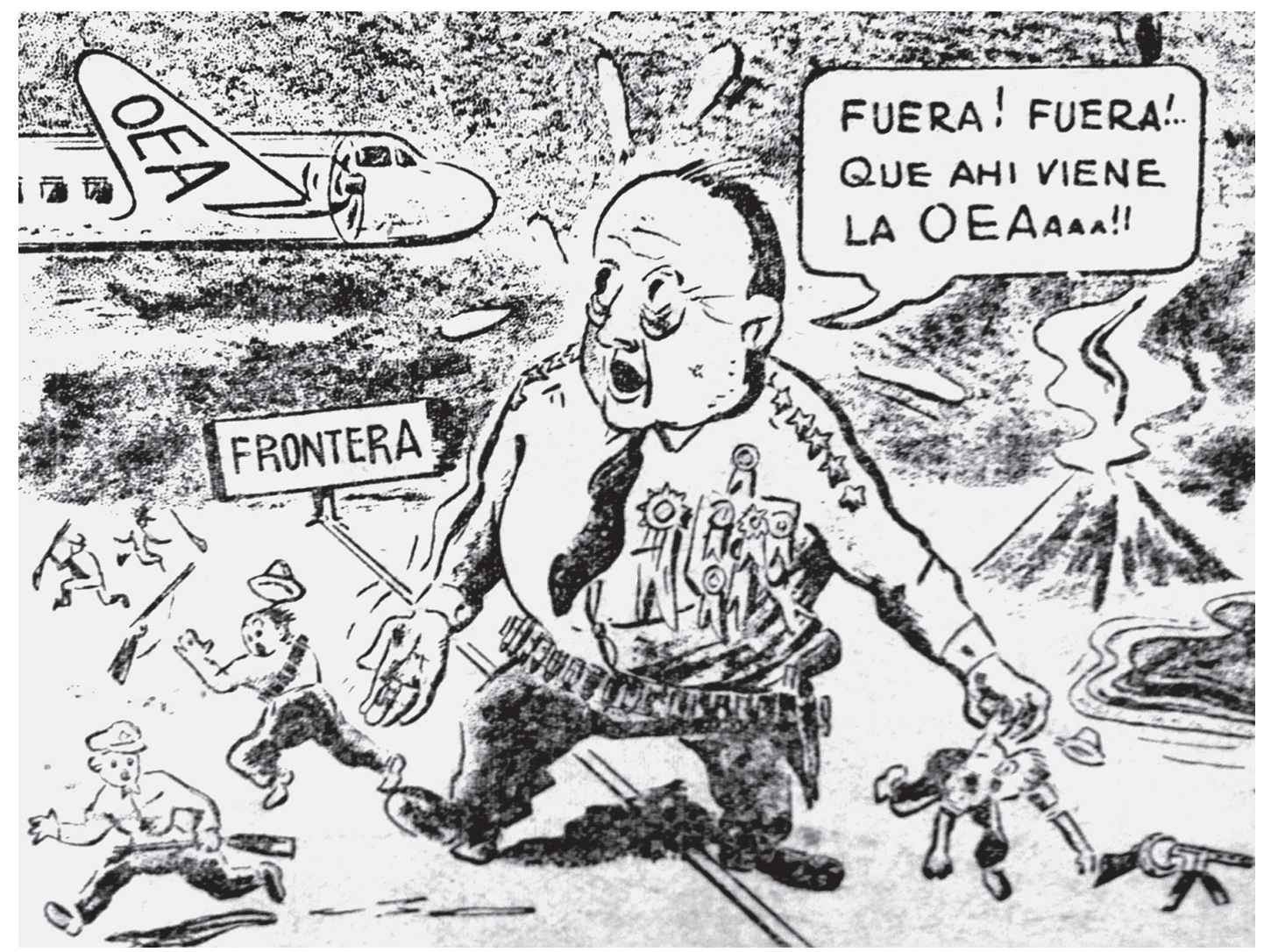

Fuente: La República, 19 enero de 1955: 16.

Existe una clara representación de Somoza como un hombre que tiene características opuestas al presidente Figueres. Justamente, como menciona Suonpää (2010), las actitudes acerca de un grupo o una población "enemiga", en la mayoría de los casos se forman con la comparación y el contraste con las características propias.

El presidente del Congreso costarricense, Gonzalo Facio, mencionaba al referirse a Somoza: "yo lo que creo es que está sufriendo de delirio de persecución, y que trata de justificarse ante su propio pueblo que lo repudia" (La República, 10 enero de 1955: 4), mientras que Figueres se presenta en un reportaje de La Nación escrito por Julián Weston como un político que "desde que ocupó el poder en 1953... ha aumentado su popularidad personal. Una demostración de esto se produjo en medio de la entrevista con este corresponsal. Se escucharon vivas en la calle frente a su casa" 
(La Nación, 20 de enero de 1955: 22). El supuesto apoyo de la población costarricense a Figueres se contrasta con la impopularidad de Somoza.

En el periódico La República se creó una sección llamada "Para que abra los ojos la OEA", donde se señalaban los elementos que debía conocer la Organización para cuando diera su juicio sobre el conflicto. En esta sección se decía que Somoza "no ha estado nunca en ningún combate, ni ha estudiado en ninguna escuela militar. Sin embargo, se ha hecho dar el apodo de General de cinco estrellas" (La República, 15 de enero de 1955: 2).

En este misma sección constantemente se hacía burla de su persona hasta el punto de compararlo con un animal: "Somoza es como los caimanes: insaciable. Precisamente, el pueblo de Nicaragua lo ha bautizado con ese apodo de animal feroz. Y él, cínico, goza hasta cierto punto con el cognomento" (La República, 18 de enero de 1955: 2). Para Goseva (2010), la propaganda utilizanda en los periódicos como medio de difusión es un arma extraordinariamente potente en tiempos de guerra, porque se puede utilizar para crear una imagen negativa del enemigo, o incluso para formar una imagen falsa para convencer sobre la propia causa y conseguir apoyo.

También, la imagen que se construye de Somoza es en oposición a la democracia, como señalaba Figueres: “Nuestra democracia estorba al General Somoza. Estorba a todos los que han estado diciendo que la libertad y la democracia no son regímenes adecuados para la América Latina" (Diario de Costa Rica, 13 de enero de 1955: 1), en otro discurso de este presidente se refiere a Nicaragua de la siguiente forma:

... demasiado tiempo, mientras nuestros textos constitucionales han hablado de gobiernos representativos, de respeto a la dignidad humana, mientras tanto, las realidades en algunos países han sido las tiranias, los atropellos, las flagelaciones. Y peor aún, las invasiones de países vecinos, con el fin de establecer regimenes semejantes (La Nación, 15 de enero de 1955: 5).

En el anterior discurso, Figueres asegura de forma directa que Nicaragua, con esta invasión, pretende imponer una dictadura en Costa Rica, es decir, se presenta al país del norte Nicaragua opuesto políticamente a Costa Rica. Estas aseveraciones son de gran importancia porque, en primer lugar, Figueres había sido la cabeza de un gobierno de facto que gobernó durante 18 meses después de la guerra civil, y además porque permiten comprender los discursos de Figueres en los cuales articulaba el conflicto como un enfrentamiento entre las democracias y las dictaduras, como aseguraba en una entrevista:

... estamos frente a otro episodio de la vieja lucha planteada en América entre las dictaduras y los sistemas democráticos. Los regímenes militares de tiranos no pueden permitir que otros pueblos disfruten plenamente de garantías para ejercer sus derechos y avancen tranquilamente por el camino del progreso (La República, 15 de enero de 1955: 3). 
Durante el conflicto, Nicaragua y Costa Rica fueron representadas como antagónicas, sin embargo, cuando este finalizó hubo un cambio en las representaciones que se hacían de Nicaragua, pues se empiezan a utilizar frases como "la república hermana" y, "el pobre pueblo". Tal es el caso de un artículo de opinión de Jaramillo Valladares, en el cual se decía:

... pueblo libre, valiente y demócrata de Nicaragua, recordad para toda la vida que nosotros tenemos piedad de vuestro padecimiento y que las armas de los valientes y demócratas costarricenses no están ni estarán apuntando contra ustedes, pero sí tendrán buena puntería y estallarán contra el propio Somoza (La República, 25 de enero de 1955: 13).

Por su parte, en uno de sus discursos Somoza mencionaba que los habitantes de ambos países "están ligados por lazos familiares y tradiciones comunes" ( $L a$ República, 22 de febrero de 1955: 5). Este cambio se puede interpretar bajo el ambiente de conciliación que intentó fomentar la OEA para finalizar con el conflicto, buscando normalizar las relaciones entre ambos países, además se puede observar un cambio en los discursos de los dos gobiernos, asegurando su colaboración en las propuestas de la OEA para lograr una pronta solución.

\section{Costa Rica y José Figueres Ferrer}

En el contexto de la invasión calderonistas de 1955, Costa Rica es representada en los periódicos con una serie de atributos que forman parte de la construcción de la identidad nacional. Tratándose de una invasión al territorio costarricense apoyada por Anastasio Somoza, los discursos en la prensa se enfocan en resaltar la democracia de Costa Rica, en comparación con los países vecinos centroamericanos y latinoamericanos, especialmente con Nicaragua.

El atributo más utilizado para Costa Rica es su democracia, en un artículo escrito por la Conferencia de Uruguay y publicado en La República se aseguraba:

... hoy esos tiranos, alentados por el caso de Guatemala, que incorpora a otra dictadura más al block totalitario del continente y por la acogida cordial y la ayuda que esos regímenes han recibido y reciben de las grandes democracias, han reorganizado una fuerza más vasta, mercenaria y poderosamente armada para intentar el asalto final contra Costa Rica, contra la única y verdadera democracia que existe en Centroamérica y una de las muy pocas que quedan en el continente (La República, 19 de diciembre de 1954: 77).

Costa Rica se establece como una democracia ejemplar en América, modelo para las naciones, por lo que la invasión calderonista de 1955 se representó como una batalla que debía ganarse en nombre de la democracia, la soberanía y la libertad. 
Precisamente, González apuntaba sobre esta caracterización de Costa Rica que ... hacia el final de la posguerra, cuando el desenvolvimiento de los acontecimientos políticos y militares consolidaron y generalizaron la experiencia de la década de 1940, haciendo del otro amenazante externo (el gobierno nicaragüense) y el otro amenazante interno (los comunistas) una sola unidad, contrapuesta a una representación monolítica de la identidad nacional, caracterizada como pacífica, democrática y progresista (González, 2005: 6).

También, Costa Rica se representó en los discursos dirigidos hacia la OEA como un país débil, pequeño y desarmado que necesitaba ser protegido ante su agresor, Nicaragua, un país muy bien armado. Como se mencionaba en un artículo de Joseph Hinshaw y publicado en La Nación: "Nicaragua tiene la mayor fuerza aérea de la América Central" (La Nación, 09 de enero de 1955: 37).

El presidente de Costa Rica, José Figueres, fue representado como un defensor de la democracia, que coincide con la principal característica que se resaltó para este país. Sin embargo, es vital destacar que los calificativos de comunista y anticomunista fueron utilizados al referirse a Figueres, lo cual concuerda con el contexto de Guerra Fría en donde él no era considerado a nivel internacional como un auténtico anticomunista, sino que se dudaba de su ideología política por su intervencionismo estatal; de hecho, los enemigos políticos de Figueres utilizaban el discurso de que estaba involucrado con comunistas o ideologías de izquierda.

Como menciona Bowman (2000), para 1955 Costa Rica experimentó una crisis de credibilidad de proporciones masivas. En la cumbre de la Guerra Fría, Figueres era considerado comunista, la Central Intelligence Agency (CIA) era su enemigo y las cuatro fuerzas políticas más importantes acordaron usar la fuerza si era necesario para quitarlo del poder.

Por último, la figura del Figueres demócrata, se relaciona, con la Guerra Civil de 1948, que en el discurso figuerista ha sido justificada como una lucha contra la "dictadura" impuesta por Calderón Guardia. Como se aseguraba en un artículo del periódico cubano La Prensa Libre publicado en La República

... el golpe traicionero va dirigido contra un adalid de la dignidad humana, cuyo nombre figurará siempre en el alto pavés continental donde se inscriben los nombres de los libertadores, encabezados por Simón Bolivar: Nos referimos a José Figueres, restaurador del régimen democrático en el bello país costarricense (La Nación, 14 de enero de 1955: 9).

\section{Rafael Ángel Calderón Guardia, los calderonistas, los comunistas y Otilio Ulate}

El expresidente Rafael Calderón Guardia escasamente es mencionado en los discursos sobre la invasión calderonista de 1955. Sin embargo, la característica más 
frecuente que se le dio fue de líder de dicho movimiento invasor, por lo tanto se le atribuyó la traición a la Patria, como se mencionó en un reportaje de La Nación: "han invadido nuestra Patria deseosos de venganza y de cometer piratería, comandados por traidores de la Patria" (La República, 16 de enero de 1955: 9).

La ausencia de Calderón en los discursos de la prensa se puede interpretar como parte del propósito del gobierno de Figueres de darle un carácter internacional al conflicto, lo cual se relaciona también con la gran aparición de discursos que involucran a Somoza. La relación entre Calderón y Somoza es un elemento a resaltar, incluso en un artículo de un periódico cubano que se publicó en La Nación se decía: "El expresidente Calderón Guardia y sus secuaces, residentes al abrigo de Somoza durante años" (La Nación, 16 de enero de 1955: 12). Existe un cuestionamiento al liderazgo de Calderón en dicha invasión.

La República presenta una evidente campaña en contra de este político, en la cual valoraba el periodo en que fue presidente de Costa Rica, pues el objetivo de Figueres era "establecer en Costa Rica un régimen corrompido como el de Calderón" ( $\mathrm{La}$ República, 12 de enero de 1955: 4). Precisamente, la estrategia fue recordar los errores de ese Gobierno a la población costarricense para difundir la idea de que una mala administración volvería si los invasores lograban la victoria.

En los medios de prensa nacional no se encuentran documentados discursos de Calderón durante el conflicto armado, quizás porque él no tuvo acceso a estos. Lo anterior, se explica por la censura que se dio a la prensa y la radio, al impedirles publicar o comunicar información no oficial.

Posiblemente, al percatarse de la superioridad armamentística del gobierno de Figueres luego de la compra de cuatro aviones de guerra a Estados Unidos bajo la aprobación de la OEA, Calderón le pidió a las tropas invasoras que cesaran la lucha armada y procedieran a retirarse al territorio nicaragüense (La Nación, 09 de febrero de 1955: 5). Esta fue la única intervención directa de este político en la prensa, lo cual permite pensar que asegura que el material de propaganda enemiga puede ser utilizado como una ayuda para disminuir el prestigio del enemigo o como apoyo a la propia propaganda, según lo propone el planteamiento de Miloiu (2010: 7-8).

Evidentemente, el gobierno permitió la publicación de este comunicado de Calderón porque resultaba beneficioso para Figueres y se constituía en la evidencia del fracaso de la invasión, junto a esto, en un artículo del New York Times publicado en La República, se decía que "al propiciar una revolución desde afuera, el expresidente Rafael Calderón Guardia se ha acabado políticamente" (La República, 01 de febrero de 1955: 2).

Al mismo tiempo, los comunistas costarricenses mediante un Editorial del periódico Adelante criticaron fuertemente a Calderón al asegurar que "ha tenido de su lado grandes fuerzas políticas populares y no ha querido una lucha por la vía civil" (Adelante, 13 de marzo de 1955, s. p.), es decir, la mayor crítica a Calderón se refiere a que no quiso buscar la derrota de Figueres por medio de las elecciones. 
Los calderonistas al igual que su líder político fueron poco mencionados en los discursos de los periódicos sobre la invasión de 1955, incluso un mes antes de la invasión Figueres aseguraba en un discurso en el Congreso:

... creo que la proyectada agresión a Costa Rica, ya no se producirá. Ahora el problema está en esos grupos que todavía permanecen armados fuera del país, tratando de agredirnos, con la complicidad de algunos políticos, lo que al parecer ha fallado completamente. Considero que sería de conveniencia que esas gentes regresaran a Costa Rica, y se pusieran a trabajar al amparo de las libertades de que toda ciudadanía disfruta entre nosotros. Deben de convencerse que el Calderonismo es un capitulo cerrado en la historia de Costa Rica (La Nación, 01 de diciembre de 1954: 2).

Quizá Figueres realmente pensaba que la invasión no se efectuaría o, por el contrario, como evidencia su denuncia en la OEA, quería asegurarse de que la población costarricense le daría su apoyo ante la inminencia de dicha invasión.

El discurso más recurrente con respecto a los calderonistas giró en torno a la idea de que eran "falsos costarricenses" por formar parte de los invasores, tal es el caso de un artículo en el cual la Rerum Novarum, una central sindical, hace público su apoyo al gobierno de Figueres, al decir que "los regímenes dictatoriales y los opositores, 'falsos costarricenses', quieren ensangrentar nuestro suelo con una 'revolución' (léase guerra)" (La Nación, 07 de diciembre de 1954: 11). Como menciona Aguilar (1987), existía una estrecha relación entre esta organización sindical y Figueres; de hecho, esta autora asegura que las relaciones de la Confederación de Trabajadores Rerum Novarum (CCTRN) con el PLN y el gobierno de Figueres limitó mucho su crecimiento durante la década de 1950, porque le restó decisión y combatividad.

Por otra parte, La República, al igual que con Calderón, tuvo un discurso en contra de los calderonistas al enfatizar en la corrupción y afirmar que querían volver al "disfrute de los dineros públicos del que en hora afortunada para el país fueron arrancados en 1948" (La República, 26 de noviembre de 1954: 1).

Los motivos de la invasión no se encuentran con claridad en la prensa analizada, sin embargo, se duda si realmente existió una intencionalidad o propósito en este hecho. Obregón (1981) menciona que los exiliados calderonistas proyectaban el derrocamiento del Gobierno de Costa Rica, además de recuperar el poder que habían perdido en 1948. Mientras que Acuña (1977) recopila testimonios de calderonistas que participaron en la invasión de 1955, los cuales indican:

... entre nosotros no habia un ideal revolucionario ni pensábamos en un programa de transformación del país. Nuestro grito de protesta era: ¡Viva Calderón Guardia! Lo demás poco nos importaba", y otro participante aseguró "éramos portadores del ideal supremo de todo exiliado: ¿Queriamos volver a la patria! 
Es de gran importancia mencionar que los calderonistas nunca fueron claramente identificados como el grupo invasor, los discursos de los periódicos, fueron muy ambiguos en este sentido, y en pocas ocasiones se mencionaban como combatientes, pero en la mayoría de los casos se decía que los invasores eran mercenarios, y no precisamente se les llama calderonistas.

Cuando terminó el conflicto militar, el presidente Figueres tuvo un giro en su discurso sobre los invasores. Producto del conflicto, los presos políticos se vincularon con el calderonismo y a partir de ese momento se les empezó a llamar "calderonistas"; discurso que llegó a legitimar la persecución a este grupo político. Además, en los discursos de la prensa se trató la invasión como un conflicto interno, sin que se abandonara completamente el discurso de la invasión como una agresión externa por parte de Nicaragua.

Se podría decir que en la prensa costarricense convivieron dos discursos sobre la invasión de 1955; el primero de ellos estaba dirigido principalmente al extranjero y a la OEA, y en el cual Nicaragua era el agresor. El segundo discurso se dirigió principalmente al interior de Costa Rica, en el cual se relacionaba la invasión con los opositores al gobierno de Figueres y con los perdedores de la Guerra Civil de 1948, atacando a los calderonistas.

Esta división de las dos representaciones del conflicto no quiere decir que ambas no se encontraran presentes en algunos discursos; por ejemplo, la dimensión internacional de la invasión también es utilizada a lo interno del país, pues se fomentó el odio y el rechazo hacia los nicaragüenses, al representar a los primeros como personas con una cultura opuesta a la costarricense. Precisamente, como apunta Miloiu (2010: 7-8), la propaganda facilita la agresión, especificando los objetivos para el odio.

Por su parte, los comunistas que dieron gran relevancia al papel de Somoza en la intervención consideraban que al ser una invasión somocista, los calderonistas estaban siendo utilizados por este personaje que se aprovechaba de la popularidad que podían tener entre la población costarricense por sus antecedentes en la obra social (Adelante, 10 de octubre de 1954: 1); además, de efectuarse, la invasión sería un fracaso y "solo serviría para que los figueristas masacraran a otro grupo de 'mariachis"” (Adelante, 12 de diciembre de 1954: 1).

Aunque los comunistas no quisieron participar oficialmente en la invasión, el gobierno de Figueres se encargó de presentarlos como un grupo involucrado en dicho conflicto. Figueres en una carta dirigida a Manuel Mora mencionaba que "un buen número de los individuos que han salido hacia Nicaragua y Honduras para sumarse a la asonada invasora pertenecen al grupo llamado Vanguardia Popular, que es otro nombre el Partido Comunista" (La República, 26 de noviembre de 1954: 9). Además, aseguraba que para fomentar el ambiente de inestabilidad vivido en el país, los comunistas estaban promoviendo huelgas; al respecto, según un reportaje de La República: 
... al tenerse las primeras noticias de la invasión, los comunistas se pusieron en actividad como se sabe entre el plan revolucionario que ha sido confeccionado principalmente por los camaradas, figuran huelgas y otras demostraciones de violencia a fin de sembrar el terror y la confusión. Uno de los más activos lo fue el líder rojo Arnoldo Ferreto quien ayer mismo se trasladó a Quepos a fin de dirigir la huelga de comunistas en la Zona Bananera. Según parece el dirigente comunista notó el fracaso de las gestiones de su reducido grupo rojo, ya que la mayoría de los trabajadores no respondieron al llamado (La República, 12 de enero de 1955: 3).

La mención que se hizo de los comunistas, como parte de los invasores, fue interpretada por este grupo político como una tergiversación del gobierno sobre su posición ante el conflicto para poder justificar la represión (Adelante, 05 de diciembre de 1954: 1), pues al mencionarlos entre los rebeldes se justifica su eventual persecución.

El gobierno de Figueres, ante la emergencia, estableció una censura a los periódicos que de alguna manera pudieran informar a los enemigos o alarmar a la población con datos falsos (La Nación, 15 de enero de 1955: 9). En las noticias analizadas no se pudo establecer si el periódico Adelante fue censurado o se le prohibió su publicación, pero sí se encontró una noticia donde se informaba sobre "la acusación a los editores de Adelante, por los cargos de edición y distribución de propaganda subversiva" (La Nación, 26 de enero de 1955: 7).

Durante el conflicto, el periódico La República lideró una campaña en contra de Otilio Ulate; en este había una sección llamada "Lo que piensa el pueblo de Otilio Ulate", la cual consistía en una serie de comentarios de los costarricenses que no lo aprobaban. Asimismo Figueres se encargó de representarlo como un enemigo de Costa Rica mediante sus discursos, con acusaciones directas que lo involucraban con los invasores.

Por su parte, en el periódico Diario de Costa Rica, Ulate, a pesar de que el gobierno de Figueres lo censuró, continúo informando sobre su posición y creó una sección también denominada "Lo que el pueblo piensa de Ulate", en la cual la población costarricense partidaria de este político lo defendía y exaltaba.

Ser aliado de Somoza y de los invasores fue la acusación más frecuente que se le hizo a Ulate y esto, por ende, lo convirtió en un traidor de la Patria, así como se dijo de Calderón. En La República se publicaban artículos de periódicos latinoamericanos que enfatizaban la alianza de Ulate con Figueres durante la Guerra Civil de 1948, tal es el caso de un artículo de la Revista cubana Bohemia, de Diógenes de la Rosa, en el cual se presentaba a Ulate como un aliado de sus anteriores enemigos. Se decía: "Ulate combatió a Calderón y repudió a Somoza, y ahora va de bracete con ellos... se ha hecho instrumento, eco y colaborador de todo lo que antes había combatido" (La República, 14 de diciembre de 1954: 17).

Sobre Ulate, Torres (1986: 23) considera que luego de su gobierno se convirtió en un político desarmado, porque los sectores burgueses que lo apoyaban le restaron 
poder político ante la emergencia de otros líderes; ante esto, plantea que la participación política de Ulate para este periodo se resume en un mayor anticomunismo y antiliberalismo para intentar recobrar su imagen política y su confianza hacia los viejos sectores dominantes.

Una supuesta prueba de la alianza de Ulate con los invasores fue su oposición a la compra de armas que el gobierno de Figueres realizó antes de efectuarse la invasión. En un artículo de opinión, Óscar González aseguraba: "la abierta oposición en la compra de armas para la defensa de nuestra soberanía, que hizo dentro y fuera del país" (La República, 03 de febrero de 1955: 6), es decir, se consideró su oposición como un acto para evitar que Costa Rica pudiera defenderse de la invasión.

Tanto Ulate como Somoza son representados con características opuestas a Figueres. Al primero, se le achacaba que era un político sin ideales firmes porque cambiaba sus alianzas políticas; no era un buen patriota porque se aliaba con enemigos e invasores de la patria, y promovía el descontento entre la población costarricense al fomentar el ambiente de inestabilidad política dentro del país mediante sus diarios y radioemisoras.

Como plantea González (2005: 7) y Torres (1986: 378), Otilio Ulate Blanco, José Figueres Ferrer y sus respectivos grupos electorales se enfrentarían durante todo el decenio y no se destaca un planteamiento político con respecto al devenir del país en el campo económico o social, sino que se circunscriben a cuestiones de rencillas y celos personales.

La evidente amistad o relación de Ulate con Somoza fue interpretada como una muestra de lo "mal hijo de la patria" que era este político por aliarse con quien estaba realizando la invasión, y ante la crítica Ulate aseguró: "prefiero un abrazo con Somoza a un solo muerto costarricense" (La República, 22 de febrero de 1955: 5).

De forma paradójica, Ulate estuvo interesado en actuar de intermediario en la solución del conflicto entre Nicaragua y Costa Rica, incluso sugirió que si Figueres daba la amnistía general que había prometido brindar antes de la invasión, los opositores, a cambio, depondrían las armas (Diario de Costa Rica, 05 de febrero de 1955: 7). Esta propuesta fue ampliamente criticada en un Editorial de La República, donde se dijo que este político durante su gobierno "tuvo cuatro años para procurar la amnistía" (La República, 23 de enero de 1955: 2) y no la había dado, lo cual le restaba credibilidad a su iniciativa.

Finalmente, en un Editorial de Adelante se señalaba: "estamos con la demanda de una amnistía general que Ulate pide ahora y no fue capaz de dar tampoco durante su gobierno" (Adelante, 13 de marzo de 1955: 2). Como menciona Torres (1986: 376), la actitud de Ulate fue mantener una posición en apariencia de mediador entre las fuerzas en pugna, para sacar provecho político. La propuesta de intermediación no fue considera por el gobierno de Figueres ni por la OEA. 


\section{Combatientes y fortalecimiento militar}

Los discursos de la prensa, al referirse a los combatientes del gobierno y los invasores, se construyen a partir de constantes comparaciones. Es importante recordar que Costa Rica no tenía ejército pues había sido abolido por la Junta de Gobierno el 1 de diciembre de 1948 y la seguridad estaba en las manos de la policía nacional, además de existir fuerzas de reserva. Al momento de la invasión, el gobierno de Figueres estableció oficinas de reclutamiento ${ }^{5}$ para formar un ejército improvisado de voluntarios.

Ante esto, fueron abundantes las noticias que hablaban sobre cómo reaccionó la población costarricense ante las órdenes del presidente Figueres, tanto antes del conflicto, pues como mencionaba este mismo político "numerosos ciudadanos partidarios y amigos han llegado a ponerse a las órdenes" (La República, 26 de noviembre de 1954: 9), como durante el enfrentamiento. En un Boletín oficial "millares piden armas para defender la patria" (La Nación, 13 de enero de 1955: 13), y en otro Boletín oficial se hablaba de "miles de voluntarios para defender la soberanía nacional" (La República, 12 de enero de 1955: 3).

La cantidad de calderonistas que invadió Costa Rica y la que estaba en Nicaragua preparándose para ingresar al territorio costarricense no se puede conocer con certeza por medio de la prensa, incluso se podría asegurar que no existe una investigación que haya tenido por objetivo conocer esas cifras. Sin embargo, al respecto Bowman (2000) menciona que mientras las tensiones crecían en Costa Rica, entre 300 y 500 costarricenses contrarrevolucionarios estaban entrenando en Nicaragua.

La representación más generalizada de los combatientes invasores fue que eran mercenarios, en oposición a los costarricenses, destacados como voluntarios que se ofrecían por amor a defender su patria, también se decía de los invasores que eran malos costarricenses, bandoleros internacionales y reaccionarios. ${ }^{6}$ Además, hubo una gran ambigüedad con respecto al origen de los invasores, pues algunas veces eran representados como extranjeros y otras como nacionales. Lamentablemente, no se puede determinar la procedencia de los invasores por medio de los periódicos; sin embargo, en un informe del Gobierno se mencionaba la existencia de al menos 65 presos políticos (Diario de Costa Rica, 05 de febrero de 1955: 10) y solo se hablaba de costarricenses, todos ellos implicados con el calderonismo.

En una entrevista realizada a Miguel Ruiz, uno de los líderes del movimiento que tomó Ciudad Quesada, mencionó "nos llamaron mercenarios en Villa Quesada, cuando salimos de San José, Heredia y Alajuela" (La Nación, 05 de febrero de 1955: 9). Por su parte, González (2005) al hablar de la invasión de 1955 la describe como apoyada militarmente por Somoza y protagonizada por un cuerpo de milicianos calderonistas.

Mientras que los combatientes del gobierno eran representados con una altísima moral o una moral superior, una buena organización y táctica militar, un espíritu de victoria, valientes y patriotas (La República, 16 de enero de 1955: 2 y 5), los combatientes 
invasores eran llamados malos hijos de la patria, lo cual evidencia la participación de costarricenses. En un artículo de la sección "Para que abra los ojos la OEA" de $L a$ República, se les llamaba a los invasores filibusteros, al hacer referencia a la Campaña Nacional de 1856 (La República, 18 de enero de 1955: 2), además se decía que su moral decaía y que eran homicidas por haber derramado sangre de costarricenses entregados en la defensa de su patria.

El fortalecimiento militar del Gobierno de Costa Rica fue un tema de gran debate, pues meses antes de que se efectuara la invasión, Figueres ya tenía la intención de armarse, y en junio de 1954 había comprado medio millón de dólares en armas a Estados Unidos (La República, 12 de enero de 1955). La crítica no se hizo esperar y manifestó el temor de que el gobierno se armara, por ejemplo, los comunistas afirmaban: "si hay invasión los confites del Tío Sam servirán para llenar los cementerios de cadáveres y los hogares de luto, si no hay servirán para que la camarilla figuerista se perpetúe en el poder por la fuerza". Además, este grupo político aseguraba: "Estados Unidos le vende a Figueres un armamento y admite que le sea pagado al margen de nuestras leyes" (Adelante, 31 de octubre de 1954: 1).

Según Acuña (1977: 28), los diputados de la oposición objetaron la compra en sí, además del procedimiento empleado y la militarización del país, hasta que llegaron a la conclusión de que despotricaban en vano, pues las armas estaban en Costa Rica y centenares de jóvenes se aprestaban a recibir instrucciones sobre su manejo.

Durante el conflicto armado, Figueres presentó a Costa Rica como una democracia sin ejército, indefensa, que necesitaba de la protección de los organismos internacionales. Incluso, le solicitó a la OEA que le permitiera comprar armas bajo la justificación de que necesitaba defenderse del agresor y proteger la democracia; su solicitud fue aprobada y Estados Unidos le vendió al gobierno de Figueres "cuatro cazas Mustang al precio simbólico de un dólar cada uno...". Posteriormente, se informaba en la prensa que habían llegado al país los aviones y que el Estado Mayor no contaba con personal entrenado porque eran muy modernos (La Nación, 18 de enero de 1955: 4), pero que los estadounidenses inmediatamente instruirían a pilotos ticos. Estos aviones serían un elemento determinante en el combate, pues se obligó a los invasores a replegarse hacia Nicaragua.

Por otra parte, en un Boletín oficial del Gobierno de Costa Rica se decía que los invasores fueron armados por Somoza, y se mencionaban algunos detalles, por ejemplo que habían sido abastecidos con aviones venezolanos (La Nación, 13 de enero de 1955: 12). Como mencionó Ruíz en una entrevista que le realizó Bowman (2000: 109): “Si hubiéramos tenido nuestra propia clase militar y no hubiéramos necesitado obtener las armas por medio de Somoza, hubiera sido simple unificar a la oposición y derrocar el figuerismo en 1955".

Precisamente, Bowman (2000: 108-109) plantea que luego de la Guerra Civil de 1948 no se consolidó la democracia y tampoco hubo un pacto de élites, sino que los 
líderes políticos oposicionistas se aliaron para quitar a Figueres del poder; sin embargo, este autor establece que sin un ejército con el cual aliarse, los opositores a Figueres estuvieron forzados a depender del apoyo de Somoza.

El contraste entre Nicaragua, un país con ejército, y Costa Rica, una nación sin fuerzas militares, fue un elemento clave en los discursos ante la OEA, como se mencionó en un artículo escrito en Washington por Joseph Hinshaw y publicado en el periódico La República

... el gobierno costarricense no tiene fuerza aérea y su único contingente, que pudiera compararse con un ejército, es el cuerpo de la policía nacional cuyos efectivos están armados únicamente con armas menores. Nicaragua, por su parte, tiene la mayor fuerza aérea de la América Central (La Nación, 9 de enero de 1955: 37).

En los inicios del conflicto armado, La República aseguraba que los invasores estaban muy bien armados y contaban con refuerzos y alimentación (La República, 12 de enero de 1955: 3); este discurso era conveniente para Costa Rica con el fin de llamar la atención de la OEA. Sin embargo, cuando estaba por terminar el enfrentamiento armado se modificó el discurso enfatizándose en la representación del gobierno de Costa Rica como superior en armamento.

En una entrevista realizada por Acuña (1977: 37) a uno de los participantes de la invasión de 1955 llamado Alfonso Ayub planteaba la idea de que "jamás en la historia de Costa Rica hubo algún grupo que recibiera la preparación que nosotros recibimos". Este es un testimonio que permite analizar cómo se percibían a sí mismos los combatientes invasores y plantea la necesidad de estudiar con mayor profundidad el entrenamiento que recibieron en Nicaragua.

El gobierno de Costa Rica construyó un discurso en contra de los combatientes, sus estrategias y su armamento, en el cual aseguraba que ellos tenían armas más modernas, mientras que los invasores se presentan como derrotados, incluso en un Boletín oficial del gobierno de Costa Rica se decía que estos tenían que vender sus armas a cambio de alimento (La Nación, 18 de enero de 1955: 15), lo que posiblemente quería mostrar que los combatientes habían sido abandonados por sus líderes que no habían podido ni cubrir sus necesidades alimenticias.

\section{Patriotismo y motivación}

Este segundo apartado se propone analizar los discursos patrióticos y de motivación que se dirigieron a los combatientes, enfatizando en los que surgieron principalmente desde el Gobierno de Costa Rica. También se pretende identificar de qué forma los acontecimientos históricos de la Campaña Nacional de 1856 y la invasión de diciembre de 1948 fueron retomados en los discursos durante la invasión calderonista de 1955. 
Para conocer cómo los discursos formaron parte de las estrategias utilizadas por el Gobierno con el objetivo de mantener el apoyo de la población costarricense en general y lograr que los combatientes continuaran la lucha y el apoyo a la causa de Figueres.

Durante la invasión calderonista de enero 1955, el Gobierno de Costa Rica articuló un discurso en el cual luchar contra los combatientes del gobierno y apoyar a Figueres eran símbolos de patriotismo, pues significaba estar del lado de un régimen legítimamente establecido por medio de elecciones y defender la soberanía de un país agredido desde el extranjero.

Sobre el uso de la propaganda para inspirar a un ejército de ciudadanos y lograr mantenerlos en el campo de batalla, Pretorius (2009) realiza un interesante trabajo en el cual asegura que se puede ejercer un impacto significativo en la moral de los combatientes. Además, aborda el uso de la religión para difundir la percepción de que la causa política y militar es justa y noble ante Dios. También asegura que la prensa, además de publicar verdades que les convienen, da a conocer medias verdades y mentiras con la función de alentar e inspirar a los combatientes.

Los discursos patrióticos encontrados principalmente en el periódico oficialista La República y en los boletines del Gobierno publicados en todos los periódicos que se analizaron, giraron en torno a dos elementos principales; la figura de Figueres como un buen líder político a quien se debía seguir y la lucha por la defensa del territorio de Costa Rica.

Como plantea Pretorius (2009), las personas que dirigen la propaganda utilizada en un contexto de guerra escogen cuáles son los acontecimientos o temas importantes para la sociedad, es decir, parten de la idea de que la información pasa por una selección y es parcializada. En el caso que estudia este autor se destacan elementos como un patriotismo generalizado, el amor a la libertad y el nacionalismo. En ese caso, por tratarse de una invasión, se resalta el uso de elementos como la libertad y la soberanía.

La unidad patriótica que se promovió desde el Gobierno, durante la invasión, solo involucraba a un sector de la población costarricense que excluía a los calderonistas, comunistas y personas relacionadas de alguna forma con los invasores. Mientras que otro grupo reclamaba un patriotismo que se reflejaría en una unidad nacional que incorporaría a toda la población del país, como se constata en este comunicado de la Alianza Costarricense de Mujeres, afín al Partido Vanguardia Popular

Exigimos al gobierno y a todos los dirigentes de la politica nacional una actitud patriótica $y$ digna, de verdadera unidad nacional sin discriminaciones para ningún sector social, sin restricciones para la libertad de pensamiento y de organización. Las virtudes cívicas de los costarricenses y los principios democráticos deben ponerse a prueba en esta hora, para resolver problemas nacionales sin intervención extranjera (La República, 26 de noviembre de 1954: 8).

Cuando los invasores fueron descritos por la prensa calderonista, eran representados como personas sin valores patrióticos; en un reportaje de La República, 
se afirmaba que pertenecían a un grupo que "no ha mostrado jamás preocupación patriótica alguna, lo único que les interesa es regresar al disfrute de los dineros públicos del que en hora afortunada para el país fueron arrancados en 1948" (La República, 26 de noviembre de 1954: 9).

Además, se creó la imagen de un costarricense que ante la crisis de la invasión se entregaba a favor de su país, ya fuera ofreciéndose para luchar en el campo de batalla o poniendo a disposición del Gobierno cuanto poseía. Ante esto, fueron frecuentes las noticias de ofrecimientos al Gobierno en los boletines oficiales, en una de ellas se indicaba: "la gente acude a casa del presidente a ofrecer sus vidas y propiedades en defensa del país" (Diario de Costa Rica, 12 de enero de 1955: 2).

Por otra parte, se informaba que los funcionarios públicos donaban "porcentaje de sus salarios en contribución con el Fondo de Defensa Nacional" (La Nación, 21 de enero de 1955: 8). Incluso, la figura del costarricense campesino, que forma parte de la construcción de la identidad nacional, era utilizada en estos discursos asegurándose de que "sin rodeos ni vacilación trocaron sus herramientas por las armas" (La Nación, 27 de enero de 1955: 6).

El respaldo de las fuerzas armadas de voluntarios se argumentó como un apoyo al país y no precisamente a la figura de Figueres como político, en un segmento de opinión donde Castro (1955) hizo un llamado a la población advirtiendo que

... ahora no se trata de ser o no ser figuerista, porque al menos yo no lo soy, y me sentiré honrado cuando esté confundido entre las filas de los defensores de la patria. De lo que se trata es de permitir o no que por encima de nuestro orgullo personal de ser costarricenses vengan un par de dictadores a cambiar nuestro sistema democrático... (La Nación, 16 de enero de 1955: 29).

El ejército improvisado encargado de organizar el gobierno de Figueres ante el ataque de los invasores fue la mayor representación del fervor patriótico utilizado en los discursos gubernamentales, especialmente por el enlistamiento voluntario. El entregarse al Gobierno, incluso ante la posibilidad de perder la vida en el campo de batalla, es representado como una acción de máximo amor a la Patria y defensa de la soberanía nacional, y quienes murieron en la lucha armada fueron representados como héroes. Tal es el caso de uno de los boletines oficiales del Gobierno que aseguraba que los combatientes "no pedían nada y estaban dispuestos a darlo todo", incluso algunos que estaban heridos "pedían se les enviara a primera línea" (La Nación, 22 de enero de 1955: 4).

Con respecto a los discursos motivacionales, Pretorius (2009) asegura que estas tienen como objetivo inspirar a un ejército de ciudadanos y mantener en el campo de batalla a los hombres que están combatiendo. Para nuestro caso, en los discursos motivacionales el gobierno enfatiza que la lucha es nacional, y en ella no solo están peleando los combatientes en el campo de batalla, sino que el Gobierno también está luchando mediante la denuncia a la OEA. 
También, otros sectores de la población contribuyen con estos discursos, tal es el caso del sector industrial del país, el cual mediante la Cámara de Industrias publicó en un comunicado

... la Nación no está dando la batalla solo en los campos de combate, fertilizando su tierra con la sangre de sus hijos que se han prestado a defender su integridad, sino también ha venido luchando en el campo jurídico internacional a fin de sustentar la fe de los pueblos en el organismo llamado a ejercer su poderosa y benéfica influencia para que ni vidas preciosas, ni recursos inapreciables ni territorios indispensables para el común y fructifero desarrollo de un pueblo dedicado al trabajo, sea presa de la constante amenaza extranjera (Diario de Costa Rica, 21 de enero de 1955: 2).

La opinión de Costa Rica en el extranjero y especialmente la de otros gobiernos fue explotada por el gobierno de este país para demostrarle a la población que el apoyo a Figueres trascendía las fronteras nacionales. Se publicaban noticias en donde presidentes o representantes de otros países aseguraban estar en la lucha con Figueres, quien a su vez aprovechaba sus discursos para mencionar que recibía "una lluvia de mensajes de apoyo de toda América" (La Nación, 12 de enero de 1955: 3), lo cual legitimaba su lucha contra los invasores.

Los discursos motivacionales del Gobierno fomentaban el enojo contra los invasores o "traidores" y, a su vez, promovían el apoyo a Figueres, principalmente mediante la utilización de las ideas de "victoria" y "triunfo". En los boletines oficiales se afirmaba que el resultado inminente sería la victoria de los combatientes del Gobierno $\mathrm{y}$ al informarse sobre los enfrentamientos siempre se mencionaba que estaban en posición de ventaja y que el triunfo estaba próximo.

Enfatizar en la cercanía del triunfo fue una estrategia para que los combatientes no se desmotivaran ni dejaran el campo de batalla. Se podría asegurar que el Gobierno de Costa Rica nunca emitió un comunicado en el que dejara vislumbrar la mínima idea de derrota. En un discurso radiofónico que luego se publicaría en la prensa, Figueres aseguraba: "ganaremos con la Ley de la Justicia... Esperemos con calma... porque tenemos armas que se adquirieron en forma previsoria. Tenemos hombres que saben usarlas, y sobre todo tenemos la firme determinación de triunfar" (Diario de Costa Rica, 13 de enero de 1955: 2).

Además, se hace gran énfasis en la actitud de los combatientes al sugerirse que una buena actitud ante la batalla puede darles el triunfo, como se observa en el siguiente comunicado:

El Estado Mayor hace saber a la ciudadanía que puede confiar plenamente en la capacidad de los estrategas que conducen las acciones, en la altísima moral de nuestros hombres y en la superioridad del armamento moderno con que están equipadas. Estos tres factores unidos a la decisión 
de vencer que alienta en todo buen costarricense determinarán indudablemente la victoria final en esta lucha contra las fuerzas invasoras (Diario de Costa Rica, 15 de enero de 1955: 1).

Cuando los invasores tomaron Ciudad Quesada el 11 de enero de 1955, el Gobierno envió sus tropas a luchar por retomar esta ciudad y los boletines oficiales aseguraban que a la entrada de los combatientes hubo un júbilo indescriptible de los vecinos (La Nación, 13 de enero de 1955: 11), lo cual demuestra la idea de estas personas como salvadoras esperadas por los habitantes, mientras que, según se decía, "no hubo un solo vecino que cooperara con los invasores" (La República, 13 de febrero de 1955: 4).

En resumen, se pueden identificar tres componentes en los discursos motivacionales del Gobierno. En primer lugar, el supuesto apoyo de la población costarricense al Gobierno y sus combatientes; en segundo, la ayuda internacional, específicamente de América Latina a la lucha de Figueres por mantener la soberanía de Costa Rica, y en tercer lugar la inminencia de la victoria y el avance hacia el triunfo con cada enfrentamiento.

En los discursos construidos desde el Gobierno, en torno a la invasión calderonista de 1955, se utilizaron acontecimientos históricos que fueron recordados e interpretados a la luz de los sucesos vividos. Sobre la interpretación clásica que consideraba que ganar una guerra era un proceso puramente militar, para Miloiu (2010) esta no es un fenómeno independiente, y la diplomacia y la propaganda son dos elementos a considerar, pues influyen en las personas involucradas en el conflicto y, además, se utilizan en función de ganar la batalla. Además, llama la atención sobre el uso de la historia y plantea que su empleo como un elemento de propaganda es un recurso o mecanismo mucho más antiguo que la creación de las instituciones, las cuales tienen como misión la propaganda, pero que aún se continúa utilizando como un elemento legitimador.

El apoyo de Anastasio Somoza a la invasión calderonista de 1955 y el hecho de que este grupo ingresara al país por la frontera norte con Nicaragua generaron un discurso que comparaba el ingreso de los filibusteros a Costa Rica y los acontecimientos ocurridos en 1856-1857, con el presente conflicto. En un discurso, Figueres mencionaba:

... con orgullo puedo manifestar que cuando algún peligro contra la libertad y la dignidad se le han presentado a Costa Rica estos han provenido del exterior. Precisamente en 1956 hará un siglo en que de Nicaragua nos vino el peligro contra la libertad y Costa Rica acudió a defender a la hermana república (La República, 12 de enero de 1955: 4).

Como se mostró anteriormente, el papel de Costa Rica es de defensor, mientras que a Nicaragua se le representa como un territorio desde donde le llegan a Costa Rica amenazas contra su libertad y soberanía, precisamente esta es una de las denuncias que el país presenta ante los organismos internacionales. 
Con respecto a la utilización de héroes o personajes históricos dentro de los discursos patrióticos y de motivación, Pretorius (2009) describe un caso en el cual señala que gente a menudo se desanima cuando sufre de hambre y tiene privaciones, pero cuando recuerda las gloriosas hazañas de los antepasados, las personas pronto se llenan de valentía y alegría y, en su caso específico, de estudio. Además, menciona que esto los condujo, incluso, a gritar que iban a luchar hasta la muerte. Por lo anterior, es de gran importancia conocer las relaciones entre los discursos y la utilización de los hechos históricos de relevancia como elementos de motivación.

Durante la invasión fue recurrente el recuerdo de los héroes que en el pasado dieron su vida en la lucha por defender a su país, esto se puede observar en el fragmento de un poema de Roberto Castro Ureña llamado "A Costa Rica", que decía

¡Oh muertos valerosos, de pasadas conquistas, que en épocas pretéritas de gloria se cubrieron! ¡Salid de vuestras tumbas, decidle al bucanero que somos vuestros hijos y vuestra tradición!

(La República, 20 de enero de 1955: 11)

La Campaña Nacional de 1856-1857 fue un acontecimiento utilizado por el Gobierno para recordarle a los costarricenses que la soberanía había sido amenazada en el pasado y que los buenos patriotas en esa ocasión lucharon y entregaron sus vidas para defenderla. Como apuntaba Castro (1955) en una sección de opinión en la cual impulsaba a la población a salir a luchar por una "soberanía alcanzada con sangre por el heroísmo de nuestros antepasados" (La Nación, 16 de enero de 1955: 29).

El espacio geográfico que albergaba a los invasores en 1955 coincidía con el territorio donde se dieron enfrentamientos contra los filibusteros, elemento que contribuyó a ela comparación de ambos conflictos. En un discurso Figueres advertía:

... es real, tenemos un pedazo del territorio invadido, tenemos precisamente aquel pedazo de territorio nacional que fue en 1856 tuvimos que ir a liberar de los filibusteros. Aquel pedazo de terreno por donde entraron también los invasores en el 48, lo tenemos ahora fuertemente invadido (La Nación, 15 de enero de 1955: 5).

El recuerdo de los costarricenses que entregaron su vida en la lucha contra los filibusteros fue muy utilizado en los discursos de la prensa. Además, se hace una comparación de estos combatientes, especialmente Juan Santamaría, con los combatientes del Gobierno ante los invasores calderonistas, asegurándose que la de estos a favor de la libertad es igualmente valiosa que la muerte de este héroe nacional.

En un artículo de opinión, Pedro Quince Clará se refería a los combatientes que morían como "caídos como un Juan Santamaría que con el sacrificio de su heroica 
vida desterró a los filibusteros" (La República, 19 de enero de 1955: 7), mientras que Alberto Cedeño, un estudiante del Liceo de Costa Rica, mencionaba "los caídos están en la Gloria al lado de Juan Santamaría, el general Cañas y León Cortés porque al defender su patria ganaron del Todopoderoso el eterno premio" (La Nación, 23 de enero de 1955: 3).

El enfrentamiento armado de mayor magnitud durante la invasión de 1955 ocurrió en el territorio de la Casona de Santa Rosa. En la imagen 2 se puede observar un grupo de combatientes del Gobierno en dicha Casona. Joaquín Vargas Gené, uno de los periodistas que estuvieron en esta zona durante el enfrentamiento, afirmaba que había sido "la más intensa batalla que posiblemente se haya verificado en toda la historia del país" (La Nación, 18 de enero de 1955: 8-9). En otro artículo de opinión, Azofeifa la describió como "la más sangrienta batalla que registra la historia" (La Nación, 23 de enero de 1955: 3). Fue en este enfrentamiento cuando murió la mayoría de los combatientes caídos en el campo de batalla y la prensa se encargó de exagerar la dimensión y las pérdidas humanas en este conflicto, como se verá más adelante.

Imagen 2

COMBATIENTES EN LA CASONA DE SANTA ROSA

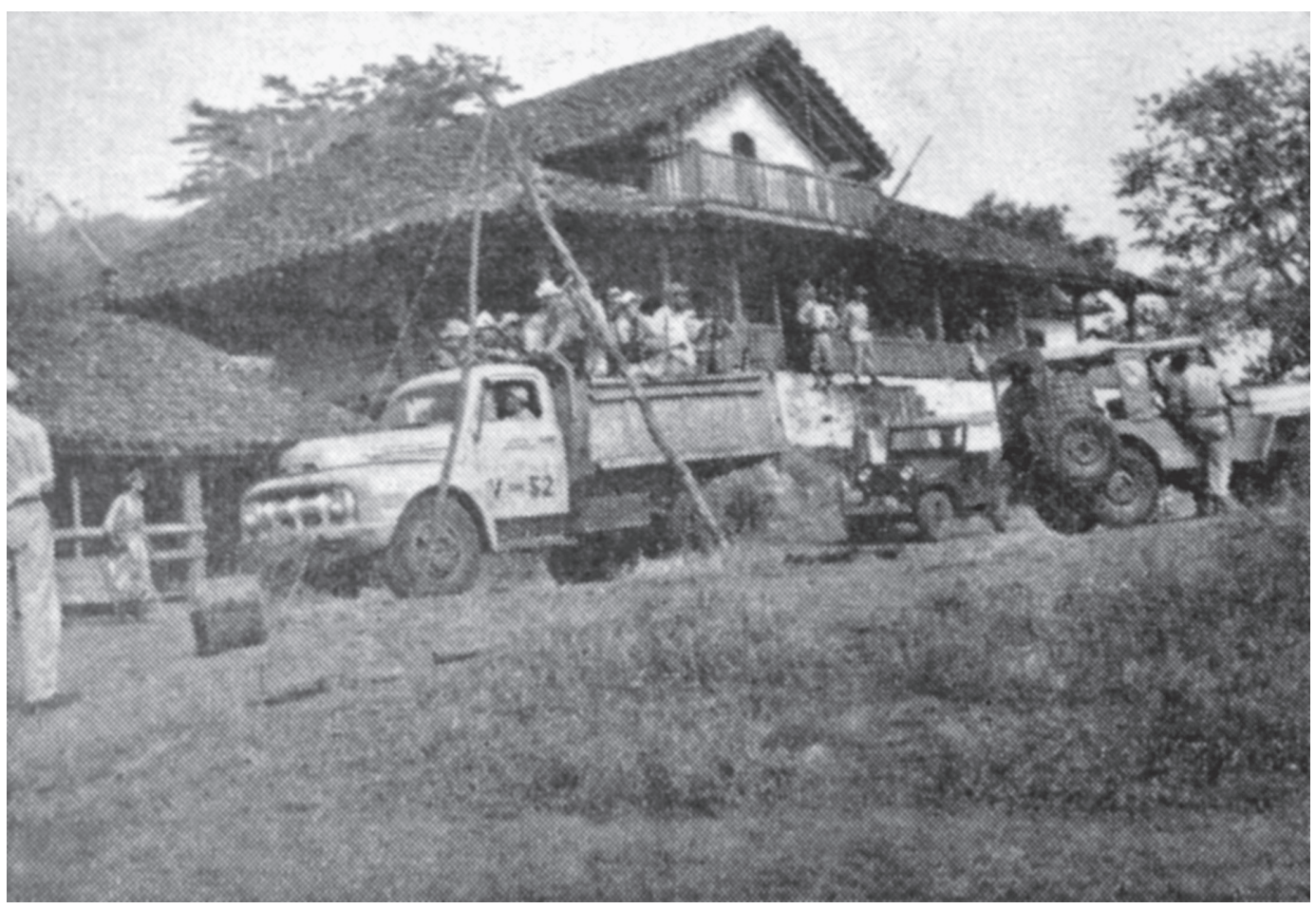

Fuente: La Nación, 18 de enero de 1955: 9. 
La Batalla de Santa Rosa, nombre con el cual se le conoció, fue un acontecimiento utilizado en los discursos para exaltar el trabajo de los combatientes del Gobierno y su victoria, como se observó en un boletín oficial que se refería a este acontecimiento:

En Santa Rosa, 45 soldados de los 150 que componían la Compañia, se batieron como leones contra fuerzas superiores en número y armamento, y las vencieron a base de coraje, de moral y de patriotismo. Cada uno de los 45 que pelearon en Santa Rosa en la primera batalla del sábado pasado, es un verdadero héroe nacional (La Nación, 22 de enero de 1955: 22).

El recuerdo de la Campaña de 1856-1857 fue un elemento de gran importancia en los discursos sobre la invasión de 1955, incluso cuando el vicepresidente de Estados Unidos, Richard Nixon, visitó Costa Rica en febrero de 1955, contribuyó a legitimar este discurso, pues en su itinerario por el país depositó una ofrenda floral sobre el monumento construido en homenaje a Juan Rafael Mora (La Nación, 20 de febrero de 1955: 30).

El año de 1948 está presente en los discursos fundamentalmente por dos motivos, en primer lugar a la Guerra Civil y en segundo porque en diciembre de ese mismo año hubo una invasión calderonista que ingresó por la frontera con Nicaragua, en condiciones muy similares a las de 1955. En noviembre de 1954 en un artículo de opinión anónimo se mencionaba: "ya en 1948 las tropas del codicioso Somoza tuvieron que regresar destempladas de una incursión sobre Costa Rica" (La República, 01 de diciembre de 1954: 2), discurso que representaba a Nicaragua como un constante invasor.

El periodista Óscar Castro Vega escribió un artículo para un periódico de la Universidad de Illinois, en el cual decía que "la idea de deponer al gobierno de Costa Rica no es nueva, en 1948 tuvimos la misma clase de dificultades; mercenarios entrenados en Nicaragua invadieron mi patria. Entonces Costa Rica apeló por primera vez en la Historia Contemporánea de Latinoamérica a la OEA" (La República, 22 de enero de 1955: 3). Este último elemento es importante porque legitima los discursos donde se presenta a Costa Rica como una república democrática que acude a las leyes antes que a las armas.

El gobierno de Figueres, especialmente por medio del periódico La República, buscó transmitir a la población el discurso de que el avance en la democracia de Costa Rica en 1948 no podía descuidarse, por lo que defender al país de los invasores calderonistas era necesario para evitar a un régimen no democrático, aliado con el comunismo, como se decía del gobierno de Calderón Guardia.

\section{Discursos sobre las victorias y derrotas}

En este último apartado se analizan los discursos de las derrotas y las victorias, tanto del Gobierno como de los calderonistas en la prensa, esto se realizará principalmente mediante los comunicados oficiales que emitía el Estado, en los cuales informaba 
a la población costarricense sobre el desarrollo de los acontecimientos durante la invasión calderonista de 1955 y los enfrentamientos entre ambos bandos.

Como menciona Schweizer (2008), en la prensa no es importante solamente la manera en que se relatan los hechos sino su escogencia, porque este "casting" de los hechos forma parte de la argumentación a favor de una política en particular o de una personalidad. Por lo anterior, es de suma importancia conocer cuáles hechos fueron seleccionados y quiénes tienen la función de narrarlos en los periódicos e intentar contrastar los discursos con los hechos.

También, es importante considerar que además de que los periódicos seleccionan los hechos sobre los cuales van a comunicar e informar, las noticias tienen la capacidad de ejercer un impacto significativo en la moral de los combatientes (Petorius, 2009). Partiendo de estos argumentos, se ha advertido desde el inicio del conflicto cómo el Gobierno costarricense insistió en que tenía un "completo control del territorio" ( $\mathrm{La}$ Nación, 12 de enero de 1955: 5).

De parte del Gobierno hubo un esfuerzo por comunicar en detalle las pérdidas humanas de los invasores e informar sobre cantidades específicas o aproximadas de capturas realizadas de calderonistas. Así, las bajas del Gobierno fueron omitidas o narradas con ambigüedad. Por mencionar un caso, sobre el primer enfrentamiento en Ciudad Quesada, el Gobierno en un principio informó que no habían sufrido bajas y había logrado capturar a veinte rebeldes. Sin embargo, más adelante, en el mismo artículo se confirma que hubo un combatiente del Gobierno que perdió la vida y, además, se afirmaba la captura de uno de los rebeldes, aparentemente jefe del movimiento de Villa Quesada (Diario de Costa Rica, 13 de enero de 1955: 2 y 4).

En el caso anterior se puede observar una dinámica que aparecerá de forma constante en las informaciones del Gobierno, es decir, se hace énfasis en la cantidad de "enemigos" heridos o muertos, siendo siempre mayor a la del Gobierno. Una noticia en La República sobre este mismo enfrentamiento de Ciudad Quesada mencionaba que estaban "levemente heridos un teniente y un raso" (La República, 12 de enero de 1955: 3). En otras palabras, los adjetivos utilizados tienen como objetivo no alarmar a la población con las pérdidas del Gobierno y mostrar sus bajas como una situación de poca gravedad.

Al referirse a la propaganda, Goseva (2010) subraya que al estar dirigida a una población definida, busca crear una percepción y un comportamiento determinados hacia un objeto en específico, por ello en la mayoría de los casos, la propaganda presenta información seleccionada, e incluso cuando se transmiten datos correctos se usan palabras cuidadosamente escogidas que no siempre representan la realidad.

Por mencionar otro de los casos sobre el enfrentamiento que se llevó a cabo a orillas del Río Peje, en el Diario de Costa Rica se indicaba que el Estado Mayor informaba que "muchos rebeldes murieron o quedaron heridos en Villa Quesada, y que las fuerzas gobiernistas solo tuvieron un muerto en la lucha de Río Peje, mientras que los 
enemigos restantes habían huido a los bosques" (Diario de Costa Rica, 13 de enero 1955: 2). En la anterior narración se puede observar la vaguedad con que se informaba sobre los acontecimientos, por ejemplo, al utilizar el adjetivo "muchos" para caracterizar a los rebeldes que murieron.

Sobre los comunicados donde se informa sobre los enemigos, Pretorius (2009) advierte que en ocasiones se exageraba sobre las bajas enemigas o sus contratiempos y se ocultaban los propios reveses. Como se ha mencionado anteriormente, la Batalla de Santa Rosa fue el enfrentamiento de mayor magnitud durante la invasión calderonista de 1955; Álvarez (1980: 9) menciona que "fue un duro golpe para las fuerzas leales del gobierno, que fueron derrotadas y dispersadas". Precisamente, como plantea Pretorius (2009), los discursos sobre los acontecimientos ocurridos en esta batalla son una clara muestra de la manipulación de información por parte de la prensa oficialista.

El Estado Mayor General de Costa Rica informaba el 19 de enero de 1955 que "el comandante de los invasores, Teodoro Picado, hijo, había perdido la vida en el frente de Santa Rosa, junto con 34 de sus hombres, y que tenía plena confirmación de su muerte", adelante se afirmaba "35 invasores murieron y 60 quedaron heridos y las bajas del gobierno llegaban a 4 muertos y 178 heridos (Diario de Costa Rica, 19 de enero de 1955: 1).

En un Boletín oficial del Estado Mayor publicado en La Nación el 20 de enero de 1955 se decía:

... el Alto Mando de las fuerzas gubernamentales informa que las tropas del gobierno se anotaron un resonante triunfo en las batallas libradas ayer al norte de Santa Rosa. Las bajas infringidas a los invasores, entre muertos y heridos, suman una cifra considerable, pudiéndose afirmar que los muertos ascienden cuando menos a 15 y que se capturaron grandes cantidades de equipo bélico (La Nación, 20 de enero de 1955: 22).

En el mismo periódico y fecha, otro Boletín oficial del Estado Mayor asegura que:

El recuento del material bélico capturado confirma que realmente la cantidad de rifles, cascos, municiones y otros equipos capturados, es asombrosa. Se está procediendo a la identificación de los muertos entre los invasores, los cuales suman varias docenas (La Nación, 20 de enero de 1955: 22).

A partir de las últimas citas se puede mostrar que el Gobierno no fue congruente con la información que enviaba a los periódicos en los boletines oficiales. Además, debido a la censura, estos informes eran los únicos que se permitían publicar. Como se ha podido observar, la cantidad de fallecidos específicamente durante la batalla de Santa Rosa nunca estuvo clara en los discursos gubernamentales, se mencionaron datos como "35 muertos", “al menos 15 muertos" y vagamente "varias docenas". 
Para Goseva (2010), a la información sobre las victorias se le asigna un lugar central en los periódicos, siendo recurrente el ocultar hábilmente las derrotas, con el propósito de redirigir deliberadamente la atención de los lectores hacia las grandes pérdidas que sufren los enemigos. Por ejemplo, en algunos casos no se publica sobre las propias pérdidas humanas o las batallas perdidas con el objetivo de influir en las percepciones que se tengan sobre ciertos eventos. Lo anterior demuestra la importancia de considerar la selección de información en los periódicos y la gran subjetividad que tienen al informar al público.

Las diferentes formas de describir las muertes de los invasores estaban cargadas de adjetivos que construían una representación trágica y hasta repugnante de estos acontecimientos, tal es el caso de un Boletín oficial que narraba:

... hay determinados puntos del antiguo frente de batalla, donde los integrantes de las patrullas tienen que rodear porque los cadáveres insepultos de los invasores, materialmente hacen irrespirable el aire. Recién ahora es posible darse cuenta de la enorme cantidad de bajas sufridas por los invasores... En los pastizales, a las orillas de los caminos, en las barrancas y por todos lados aparecen cadáveres insepultos, muchos de ellos semidevorados por las aves de rapiña. Las autoridades sanitarias costarricenses están extremando las medidas y tomando las providencias del caso en prevención de cualquier epidemia que pudiera surgir. Por el momento se ha procedido a la incineración de numerosos cadáveres enemigos (Diario de Costa Rica, 23 de enero de 1955: 2).

Al ver la descripción anterior sobre el enfrentamiento en El Amo se puede decir que los discursos del Gobierno costarricense realmente exageraban las pérdidas humanas de los invasores; además, el tipo de narración es alarmista y debió de impactar profundamente a las familias de los calderonistas que estuvieran involucrados en la invasión. Como señala Pretorius (2009), las narraciones sobre los enemigos tienen como objetivo impactar de forma significativa la moral de los combatientes.

Por otra parte, los calderonistas que habían sido capturados en lo que se llamó labores de limpieza, según los discursos del Gobierno, habían:

... llegado al Cuartel General en un estado lamentable, casi muertos de hambre y sed, y sus relatos coinciden en afirmar que las fuerzas invasoras no transportan prácticamente a ninguno de sus heridos, sino que quien se cae es inmediatamente ultimado por los oficiales o por sus mismos compañeros (Diario de Costa Rica, 23 de enero de 1955: 2).

Sobre estos supuestos calderonistas que eran ultimados por sus propios compañeros, más adelante, en la misma noticia se afirmaba, "en cierto lugar, en las inmediaciones de El Amo, las fuerzas del Gobierno encontraron una pila de cadáveres los cuales aparentemente no habían muerto en combate pues la mayoría aparecía 
claramente como habiendo recibido el Tiro de Gracia" (Diario de Costa Rica, 23 de enero de 1955: 2).

Goseva (2010) advierte que la propaganda es utilizada en muchas ocasiones para distorsionar la verdad y sugerir ideas falsas. Además, llama la atención sobre su uso para devastar la moral de los enemigos, al establecer como una de las características principales de la propaganda, la información que provoca el odio y la intolerancia hacia el enemigo, es decir, se tiende a deshumanizar al adversario.

Precisamente, Goseva (2010) menciona que en los periódicos durante un período de guerra se publica información acerca de la "inhumana" actitud de los ejércitos con sus enemigos y en algunos casos con sus propios soldados, por lo cual pareciera que los discursos presentados anteriormente tienen la intención de poner en evidencia acciones inhumanas que hayan cometido los invasores con sus propios compañeros, quizás para resaltar su deshumanización.

En los discursos de la prensa, los combatientes calderonistas son representados como personas que no tenían convicciones firmes por las cuales luchar y que además eran desleales, traicioneros y, por lo tanto, capaces de abandonar a sus compañeros de batalla. Por lo anterior, como se puede observar en un Boletín oficial, los "capturados han dado prácticamente los nombres de todos los miembros del grupo incursionista" (La Nación, 14 de enero de 1955: 8).

La cifra más elevada con respecto a las supuestas muertes de invasores se encuentra en un Boletín oficial para la prensa y radio, en el cual se mencionaba:

... aún no se ha practicado un recuento cuidadoso de los cadáveres invasores que han sido localizados a todo lo largo de los caminos y diseminados por los campos donde hubo combates, se calcula que cuando menos 160 invasores encontraron la muerte en este fracasado intento contra la integridad de nuestra Patria" (La Nación, 25 de enero de 1955: 9).

Si se considera la supuesta cantidad de fallecidos identificados en los discursos del gobierno, más la pila de muertos mencionada anteriormente, se podría decir que según la prensa, las pérdidas humanas de los combatientes calderonistas son una cantidad superior a lo que se ha registrado en otras investigaciones. En otras palabras, las cifras de pérdidas de los combatientes invasores en los discursos fueron demasiado elevadas con respecto a la realidad, por ejemplo, algunos autores como Acuña (1977: 179) y Obregón (1981: 354) mencionan que de parte del Gobierno se registran quince muertos y de los invasores once fallecidos.

Además, hay referencias a Nicaragua o a nicaragüenses involucrados en los enfrentamientos, tal es el caso de un Boletín oficial del Estado Mayor donde habla el coronel Humberto Pacheco, quien al respecto de un enfrentamiento en territorio guanacasteco aseguró que "durante los combates de ayer se infligieron al invasor grandes bajas y se le capturó material bélico en enormes cantidades, encontrándose 
palas para cavar trincheras y cascos de la Guardia Nacional de Nicaragua" (La Nación, 20 de enero de 1955: 4).

Además, en una noticia de La República que tenía por autor "un corresponsal" se mencionaba que según noticias de fuentes oficiales se confirmaba "la muerte en la batalla de Santa Rosa de por lo menos 35 enemigos, la mitad de los cuales era de nacionalidad nicaragüense" (La República, 19 de enero de 1955: 5); aseveración que en contraste con otras investigaciones no puede ser real por la cantidad ni por la nacionalidad de los supuestos fallecidos.

El presidente Figueres en un discurso, luego de terminar los enfrentamientos armados y con el propósito de realizar un desfile de la victoria, habló de los combatientes del Gobierno fallecidos de la siguiente forma "El duelo de las familias de los compañeros caídos es duelo de todos, es duelo nacional. Con ellas debemos de compartir el orgullo de haber dado esos héroes a esta lucha patriótica" (La Nación, 25 de enero de 1955: 26).

La sangre se convirtió en un elemento destacado en los discursos, pues se representa como un líquido que riega el suelo costarricense cuando los combatientes del Gobierno fallecen, dichas muertes son representadas como sacrificios que condujeron al triunfo, como se observa en un artículo de opinión donde Azofeifa (1955) mencionaba que "la sangre derramada no fue en vano, la victoria fue nuestra" (La Nación, 23 de enero de 1955: 3).

Se puede concluir que la estrategia del gobierno en los discursos sobre las derrotas y las victorias de ambos bandos fue informar a la población con cifras y datos falsos o ambiguos, como se puede comprobar con la información sobre la cantidad de heridos y muertos de sus "enemigos", de esta forma se construyeron discursos en contra de los invasores que describieron trágicamente sus derrotas convirtiendo las pérdidas de los contrincantes en victorias para la democracia costarricense y las pérdidas humanas del gobierno en una mayor cantidad de héroes nacionales.

\section{Conclusiones}

Mediante el análisis de la invasión del 11 de enero de 1955, se ha intentado un acercamiento a la comprensión de la inestabilidad política que se vivía en Costa Rica durante la década de 1950 y que formó parte de la violencia política vinculada directamente con la Guerra Civil de 1948. Lo anterior con el propósito de cuestionar la visión de una Costa Rica pacífica y destacada por su supuesta democracia excepcional.

En la prensa costarricense convivieron dos discursos con respecto a esta invasión, en primer lugar, un discurso dirigido al extranjero y a la OEA en el cual Nicaragua era el agresor. Incluso, Figueres planteó la existencia de una lucha entre democracias y dictaduras que estaba efectuándose en Costa Rica. En segundo lugar, se presentó un discurso dirigido principalmente al interior de Costa Rica, en el cual se 
relacionaba la invasión con los opositores al gobierno de Figueres, con los perdedores de la Guerra Civil de 1948, específicamente, los calderonistas y comunistas.

Por su parte, Nicaragua fue representada en la prensa como una constante amenaza para Costa Rica, por ser el lugar desde donde se estaba planeando la invasión y reclutando a los combatientes. La principal acusación a Somoza fue la de contribuir a la invasión abriendo sus fronteras, facilitándoles armas y organizando su entrenamiento. Además Somoza fue caracterizado con atributos opuestos a Figueres, mientras el primero era relacionado con la dictadura y la impopularidad, al segundo se le vinculó con la democracia y el apoyo de la población. Sin embargo, ante la intervención de la OEA y la presencia en la región de observadores hubo un cambio en los discursos de ambos gobiernos, los cuales empezaron a manifestar su deseo de colaborar en busca de la paz.

En el inicio del conflicto se hablaba de los invasores como mercenarios y, posteriormente, empezó a cobrar fuerza su asociación con los calderonistas, lo que permitió a la vez legitimar su represión y persecución. Rafael Calderón Guardia fue escasamente mencionado en los discursos sobre la invasión, esta ausencia quizás respondió a la intención de Figueres de darle un carácter internacional al conflicto. Se aseguraba que el objetivo de la invasión era reestablecer el régimen corrompido que había antecedido a la guerra civil, por lo que se le recordó a la población los errores cometidos por el gobierno de Calderón.

El expresidente Otilio Ulate fue representado en los discursos como un aliado de los invasores y de Somoza, por lo que se le caracterizó como un traidor de la Patria. Además, fue ampliamente criticado por haber cambiado sus alianzas políticas y se decía que no tenía ideales firmes por haber roto sus alianzas de 1948. Por otra parte, los comunistas no quisieron participar de forma oficial en la invasión, incluso consideraban que de efectuarse sería un fracaso. Sin embargo, el gobierno de Figueres se encargó de involucrarlos. Por lo anterior, este grupo señalaba que el gobierno tergiversaba su posición ante el conflicto para poder justificar su represión.

Al mismo tiempo, los combatientes de ambos bandos fueron representados con características opuestas, se construyó alrededor de los gobiernistas una imagen de entrega hasta la muerte por la defensa de la soberanía de su país, más aún cuando se hablaba de los voluntarios, pues el ejército improvisado fue una muestra del fervor patriótico. Mientras que los combatientes invasores fueron mostrados como mercenarios, bandoleros internacionales y malos costarricenses.

El Gobierno de Costa Rica utilizó acontecimientos históricos para legitimar su causa, tal fue el caso de la Campaña Nacional de 1856-1857, que permitió el recuerdo de que no era la primera vez que había una amenaza que ingresaba desde la frontera con Nicaragua; además, la imagen de los filibusteros se relacionó con los invasores de 1955, mientras que se recordó a Juan Santamaría en relación con los combatientes del Gobierno. 
Los invasores fueron deshumanizados por realizar ataques aéreos a ciudades indefensas y agredir a la población desarmada. Sin embargo, estas acusaciones no se limitaron a los invasores, pues Calderón en un comunicado Calderón también pidió a los combatientes terminar con los enfrentamientos para evitar que los gobiernistas continuaran atacando civiles.

En resumen, los discursos que se construyeron en la prensa fueron utilizados como un arma política contra el adversario, lo cual garantizaba su exclusión. El gobierno de Figueres durante el conflicto estableció una censura sobre los periódicos y las radioemisoras bajo el argumento de evitar información falsa que pudiera alarmar a la población. Sin embargo, como se pudo comprobar en varios casos, los informes oficiales divulgaron información ambigua, falsa e incluso exagerada, particularmente sobre la cantidad de pérdidas humanas sufridas por los invasores. Lo anterior permite concluir que la información fue manipulada por la prensa oficialista y difundida por distintos periódicos que debieron publicar los únicos informes permitidos por el gobierno de Figueres, es decir, los oficiales.

\section{Notas}

1 Toda traducción es de mi autoría.

2 Por dar un ejemplo, ver La Nación, 11 de enero de 1955: 10.

3 Por dar un ejemplo, ver Diario de Costa Rica, 09 de enero de 1955: 10.

$4 \quad$ Por dar un ejemplo, ver Adelante, 10 de octubre de 1954: 1.

$5 \quad$ Por dar un ejemplo, ver La Nación, 11 de enero de 1955: 25.

6 Por dar un ejemplo, ver La Nación, 19 de enero de 1955: 10-11.

\section{Bibliografía}

Acuña, Miguel. ¡El 55: Te mataron hermano! San José: Librería Lehmann, 1977.

Aguilar Hernández, María de los Ángeles. Clase trabajadora y organización sindical en Costa Rica 1948-1971. Tesis de Licenciatura en Historia. Universidad de Costa Rica, 1987.

Álvarez Barrientos, Mónica Noemí. La O.E.A y el T.I.A.R frente al conflicto de 1955 entre Costa Rica y Nicaragua. Tesis de Licenciatura en Relaciones Internacionales. Universidad Nacional, 1980.

Bowman, Kirk. “Fue el consenso de las élites lo que llevó a la consolidación democrática en Costa Rica? Evidencias de la década de 1950". Revista de Historia, 41 (2000): 91-127.

Bratescu, Liviu. "Diplomacy, Propaganda and War in 1877-1878: The case of Romania". Valahian Journal of Historical Studies, 14 (2010): 247-262.

Díaz, David. "Social crisis and struggling memories: populism, popular movilization, violence and memories of civil war in Costa Rica 1940-1948". PhD Dissertation. Indiana University, 2009. 
González, Alfonso. Mujeres y Hombres de la posguerra costarricense: (1950-1960). San José: Editorial UCR, 2005.

Goseva, Vera. "The Second World War in the pages of The Overall Bulgaria (19411944)". Valahian Journal of Historical Studies, 14 (2010): 123-132.

Miloiu, Silviu. "War, diplomacy and propaganda: an introduction". Valahian Journal of Historical Studies, 14 (2010): 5-8.

Obregón Loría, Rafael. Hechos militares y políticos. Heredia: Museo Histórico Cultural Juan Santamaría, 1981.

Pretorius, Fransjohan. "Boer Propaganda During the South African War of 1899-1902". The Journal of Imperial and Commonwealth History, 37, 3 (2009): 399-419.

Rovira, Jorge. Costa Rica en los años 80. San José: Editorial Porvenir, 1987.

Schweizer, K.W. y Schumann, M. "Anglo-American war reporting 1749-63: The Press and a research strategy". Canadian Journal of History/Annates canadiennes d'histoire XLIII (2008): 265-277.

Suonpää, Mika. "War Propaganda, Cultural Stereotypes and Protestant Altruism: British Press and the Russian-Swedish War of 1808-9". Valahian Journal of Historical Studies Valahian, 14 (2010): 33-52.

Torres, José Luis. Otilio Ulate su partido y sus luchas. San José: Editorial UCR, 1986.

\section{Periódicos}

La Nación (diciembre de 1954-febrero de 1955).

La República (diciembre 1954-febrero de 1955).

Diario de Costa Rica (diciembre 1954-febrero de 1955).

Adelante (noviembre de 1954- marzo de 1955).

Alexia Ugalde Quesada. Costarricense, obtuvo su bachillerato en Historia por la Universidad de Costa Rica y es estudiante de la Maestría en Historia de esa casa de enseñanza. Se desempeña como investigadora del Centro de Investigaciones Históricas de la Universidad de Costa Rica. Es colaboradora del Servicio Jesuita para Migrantes-Costa Rica.

Contacto: alexia.ugalde@ucr.ac.cr 
